\title{
ESTABELECIMENTO DE FUNGOS MICORRÍZICOS ARBUSCULARES EM MUDAS DE Mimosa artemisiana EM DIFERENTES SUBSTRATOS
}

\author{
Andréa Hentz de Mello ${ }^{1}$ Eliana Maria Ribeiro da Silva² ; Orivaldo José Saggin Júnior². \\ ${ }^{1}$ Professora, Doutora da Faculdade de Ciências Agrárias, Universidade Federal do Pará - Campus de Marabá. \\ Marabá, Pará, Brasil, andreahentz@ufpa.br. \\ ${ }^{2}$ Pesquisadores da Embrapa Agrobiologia. Seropédica, Rio de Janeiro, Brasil.
}

RESUMO: A inoculação de fungos micorrízicos arbusculares (FMAs) é viável em mudas. Nesta fase as plantas são fertilizadas o que pode inibir os FMAs. Este estudo teve o objetivo de avaliar o estabelecimento de duas espécies de FMAs, consideradas eficientes em promover o crescimento de leguminosas e a fixação biológica de $\mathrm{N}_{2}$ em áreas degradadas, durante a formação de mudas de Mimosa artemisiana crescendo em diferentes substratos ricos em fósforo. O trabalho foi conduzido em casa de vegetação na Embrapa Agrobiologia em bandejas com 72 células, cada uma com $100 \mathrm{~mL}$ de substrato constituído de composto orgânico (30\%), solo argiloso (30\%) e areia (40\%). O experimento constou de 5 tratamentos, sendo 2 de inoculação com Glomus clarum Nicolson \& Schenck e com Glomus etunicatum Becker \& Gerdemann e 3 não inoculados. Os tratamentos não inoculados constaram de uma testemunha em substrato não desinfestado, ( $\mathrm{Ni}$ - Não tratado), uma testemunha com substrato irradiado com raios gama, ( $\mathrm{Ni}$ - Raio gama) e uma testemunha com substrato tratado com Benomyl (Ni - Benomyl). A inoculação aumentou a colonização micorrízica das raízes, e as mudas tornaram-se bem colonizadas apesar do alto nível de fósforo no substrato, o que pode garantir a sobrevivência no transplante para áreas degradadas.

PALAVRAS-CHAVE: Árvore de crescimento rápido, micorrizas, nutrição de plantas.

\section{ESTABLISHMENT OF ARBUSCULAR MYCORRHIZAL FUNGI IN Mimosa artemisiana SEEDLINGS IN DIFFERENT SUBSTRATES}

\begin{abstract}
The inoculation of Arbuscular Mycorrhizal fungi (AMF) in seedlings is feasible. In this stage the plants are too much fertilized, what may inhibit the AMF. The objective of this work was to evaluate the establishment of two AMF in Mimosa artemisiana seedlings growing in phosphorus rich substratum. The research was developed in a greenhouse condition, at the Embrapa Agrobiologia, in trays with 72 cells, each one with 100 $\mathrm{mL}$ of substratum comprised of organic matter $(30 \%)$, clayed soil $(30 \%)$ and sand $(40 \%)$. The experiment had 5 treatments, being 2 of inoculation with Glomus clarum Nicolson \& Schenck and Glomus etunicatum Becker \& Gerdemann and 3 not innoculated. The innoculation increased the mycorrizal colonization in the roots. The seedlings were well colonized despite the phosphorus level in the substratum, what may guarantee the survival in the transplant to degraded areas.
\end{abstract}

KEY-WORDS: Fast-growing tree, mycorrhizae, plant nutrition. 


\section{INTRODUÇÃO}

A maioria das áreas destinadas ao reflorestamento apresenta baixa fertilidade natural e baixo potencial de inóculo de microrganismos benéficos para as plantas, como os fungos micorrízicos arbusculares (FMAs). Estes fungos contribuem para a sobrevivência e crescimento das espécies das plantas, principalmente em ambientes estressantes (SIQUEIRA; SAGGIN JÚNIOR, 1995), onde as micorrizas arbusculares exercem grande influência na estruturação das comunidades vegetais (JANOS, 1996; JASPER, 1994; SIQUEIRA et al., 1994).

Desta forma, o conhecimento sobre a capacidade das espécies arbóreas em formar simbioses com FMAs é de fundamental importância para o sucesso de reflorestamentos, podendo determinar a necessidade ou não da inoculação das plantas na fase de formação de mudas (PERRY et al., 1987).

Carneiro et al. (1995), trabalhando com solos degradados pela retirada de seus horizontes superficiais, verificaram que a inoculação com FMAs favoreceu $o$ crescimento de mudas de Albizia lebbeck e Senna multijuga, aumentou o número de propágulos destes fungos no solo e a nodulação da Albizia lebbeck, demonstrando o efeito benéfico da inoculação para o desenvolvimento inicial de mudas e para fixação de $\mathrm{N}_{2} \mathrm{em}$ leguminosas arbóreas. Desta forma, leguminosas arbóreas fixadoras de $\mathrm{N}_{2}$ que formam micorrizas arbusculares são as mais indicadas para revegetação de áreas degradadas em condições de baixa fertilidade (FRANCO et al., 1995).

A fixação biológica de nitrogênio em plantas deixa um saldo positivo de acidez na rizosfera, com consequências importantes. Esta acidificação da rizosfera pode ser usada de forma positiva para a solubilização de fosfatos naturais como fonte de baixo custo e de disponibilidade a longo prazo de fósforo (SILVA et al., 1985). Desta forma, a adubação com fosfatos naturais na formação de mudas de leguminosas arbóreas fixadoras de $\mathrm{N}_{2}$ representa uma forma eficiente de adubação de $\mathrm{P}$ e $\mathrm{N}$ ao sistema solo-planta (FRANCO et al., 2000).

As leguminosas arbóreas que tem potencial na recuperação de áreas degradadas são tolerantes à acidez e à baixa disponibilidade de nutrientes (CARNEIRO et al., 1995). A associação micorrízica tem a capacidade de auxiliar na tolerância a estas condições ampliando significativamente a eficiência da fixação de $\mathrm{N}_{2}$ através do incremento nutricional da planta. Porém, para amenizar estes problemas em áreas degradadas, onde a acidez e a deficiência nutricional atingem limites que apenas os FMAs não solucionam, utiliza-se na formação de 
mudas altas doses de fosfatos naturais (FRANCO et al., 1992).

Como as micorrizas arbusculares são geralmente inibidas em condições de elevada disponibilidade de fósforo (KAMINSKI et al., 1994), a adição de P suficiente para otimizar o crescimento das mudas pode reduzir a colonização sendo este efeito dependente da espécie vegetal e do fungo inoculado (RHEINHEIMER et al., 1997). Segundo, Cardoso (1986), a adição de $\mathrm{P}$ não torna as plantas imunes a colonização micorrízica, apenas reduz a intensidade desta. Geralmente, em concentrações próximas do ótimo para o crescimento da planta hospedeira, já ocorre inibição da colonização micorrízica (MOREIRA et al., 2002).

$\mathrm{O} P$ inibe a colonização via nutrição da planta e a quantidade de $\mathrm{P}$ requerida para isto depende da capacidade de absorção, translocação e exigência interna da planta hospedeira (MOREIRA et al., 2002).

Em solo muito deficiente em $\mathrm{P}$, a aplicação de pequena quantidade desse elemento favorece a colonização e a esporulação dos fungos (FERNANDES et al., 1987). Como a inoculação de FMAs é feita basicamente durante a formação de mudas, principalmente quando as mudas são destinadas a revegetação de áreas degradadas, os FMAs inoculados tem de colonizar uma planta crescendo geralmente em um substrato fértil, com alto nível de P disponível. Assim, os FMAs eficientes em promover crescimento das plantas, em ambientes degradados de baixa fertilidade tem de estabelecer simbiose com as mudas em substrato considerado fértil.

Desta forma, o presente estudo teve o objetivo de avaliar o estabelecimento de duas espécies de FMAs, consideradas eficientes em promover o crescimento de leguminosas e a fixação biológica de $\mathrm{N}_{2}$ em área degradada, durante a formação de mudas de Mimosa artemisiana crescendo em diferentes substratos ricos em fósforo.

\section{MATERIAL E MÉTODOS}

O trabalho foi conduzido em casa de vegetação na Embrapa Agrobiologia, Seropédica, RJ, em bandejas de isopor com 72 células, cada uma com capacidade para $100 \mathrm{~mL}$ de substrato.

O substrato utilizado foi constituído de $30 \%$ de composto orgânico, $30 \%$ de solo argiloso e $40 \%$ de areia e fertilizado com 4 $\mathrm{kg}$ de fosfato de rocha/kg de substrato. As determinações químicas do substrato foram feitas segundo metodologias para solo da Empresa Brasileira de Pesquisa Agropecuária (1979), e revelaram $\mathrm{pH}=$ 5,8; $\mathrm{Al}=0 \quad \mathrm{cmol}_{\mathrm{c}} / \mathrm{dm}^{3} ; \quad \mathrm{Ca}^{+2}=5,4$ $\mathrm{cmol}_{\mathrm{C}} / \mathrm{dm}^{3} ; \mathrm{Mg}^{+2}=3,2 \mathrm{cmol}_{\mathrm{C}} / \mathrm{dm}^{3} ; \mathrm{P}=479$ $\mathrm{mg} / \mathrm{dm}^{3} ; \mathrm{K}=260 \mathrm{mg} / \mathrm{dm}^{3}$. Como aplicouse fosfato de rocha, analisou-se o $\mathrm{P}$ 
disponível no solo pelo método da resina trocadora de íons pelo laboratório do Instituto de Agronomia de Campinas (IAC), cujo resultado obtido foi de 125 $\mathrm{mg} / \mathrm{dm}^{3}$ de $\mathrm{P}$ disponível.

O experimento constou de cinco tratamentos, sendo dois tratamentos de inoculação de espécies de FMAs, um com Glomus clarum Nicolson \& Schenck e outro com Glomus etunicatum Becker \& Gerdemann e 3 tratamentos não inoculados (Ni), sendo o substrato sem tratamento desinfestante (Ni - Não tratado); o substrato tratado com o fungicida Benomyl (Ni - Benomyl) e o substrato irradiado com raios gama ( $\mathrm{Ni}$ - Raios gama). $\mathrm{O}$ delineamento utilizado foi de blocos casualizados com cinco repetições onde cada parcela foi composta por uma bandeja de isopor de 72 células.

O tratamento que teve o substrato desinfestado com o fungicida Benomyl, recebeu $15 \mathrm{mg}$ do ingrediente ativo seco (Formulação Pó Molhável 50\%) misturado em $1 \mathrm{~kg}$ de substrato. $\mathrm{O}$ substrato foi então umedecido na capacidade de campo e deixado secar. Após uma semana a operação foi repetida. $O$ substrato que recebeu a aplicação de raios gama, foi previamente encaminhado ao Instituto de Pesquisa, Desenvolvimento e Projetos Especiais do Exército, em Guaratiba - RJ, no qual foi aplicado a dose de 2,4 a 2,5 x $10^{6} \mathrm{rad}$ por quilo de solo por 40 minutos.
As sementes da Mimosa artemisiana foram escarificadas com $\quad \mathrm{H}_{2} \mathrm{SO}_{4}$ concentrado, durante três minutos, e após lavagem, inoculadas com rizóbio BR 3462 e BR 3609 crescidas em meio semi-sólido descritos por Vicent (1970) e usando turfa esterilizada como veículo.

No plantio abriu-se um orifício em cada célula pipetando-se neste orifício, nos tratamentos inoculados com FMAs, $1 \mathrm{~mL}$ de suspensão de esporos contendo em média 145 esporos/mL. Em seguida foram colocadas quatro sementes inoculadas com rizóbio por célula. Quando as plântulas estavam com um par de folhas definitivas, foi feito um desbaste deixando-se uma planta por célula. Foram realizadas três irrigações diárias devido ao pequeno tamanho da célula das bandejas.

Para avaliação das mudas, foram coletadas aleatoriamente três plantas por bandeja aos 45, 79 e 132 dias após a germinação avaliando-se altura; massa da parte aérea seca; colonização micorrízica; número de esporos; número de nódulos; peso de nódulos secos e teores de nutrientes na parte aérea.

Para a avaliação da colonização micorrízica, $0,5 \mathrm{~g}$ de raízes foram clarificadas e coradas conforme as metodologias de Koske e Gemma (1989) e Grace e Stribley (1991). A porcentagem do comprimento de raízes colonizadas foi avaliada pelo método da interseção em 
placa quadriculada, de Giovanetti e Mosse (1980), adaptado a partir do método de medida de comprimento de raízes de Newman (1966). Para a avaliação do número de esporos, estes foram extraídos do solo através da técnica de peneiramento úmido, (GERDEMANN; NICOLSON, 1963), seguido de centrifugação em água e sacarose a 40\% (JENKINS, 1964).

Foram avaliados os teores de N, P, K, $\mathrm{Ca}$ e $\mathrm{Mg}$ na parte aérea das plantas. $\mathrm{O}$ material da parte aérea foi seco a $65^{\circ} \mathrm{C}$ em estufa com circulação de ar, e pesado até atingir massa constante. Foi então moído e digerido com extrator nitro-perclórico $(2: 1)$ para extração $\mathrm{P}, \mathrm{K}, \mathrm{Ca}$ e $\mathrm{Mg}$ e extrator sulfúrico para extração de $\mathrm{N}$ (SILVA, 1999). Os teores de $\mathrm{P}$ foram determinados por colorimetria, $\mathrm{K}$ por fotometria de chama, cálcio e magnésio por espectofotometria de absorção atômica (SILVA, 1999), e o $\mathrm{N}$ pelo método de Kjeldahl modificado.

Os dados foram testados quanto a sua normalidade e foram submetidos à análise de variância e teste de média (Tukey 5\%), utilizando-se dos procedimentos disponíveis no programa Sisvar (FERREIRA, 1998).

\section{RESULTADOS E DISCUSSÕES}

Embora a Mimosa artemisiana seja considerada uma planta rústica, de rápido crescimento e emergência em torno de uma semana (HERINGER; PAULA, 1979), neste experimento, a emergência em todas as células das bandejas só se deu aos 19 dias. Até os 45 dias após a semeadura o crescimento das plantas foi lento. A partir dos 45 dias após a semeadura, as plantas começaram a ter um crescimento rápido, passando de uma altura média de $5,3 \mathrm{~cm}$, para uma altura média de $48 \mathrm{~cm}$ aos 132 dias após a semeadura, significando que o crescimento no período de 45 a 132 dias foi cerca de cinco vezes maior que no período de 0 a 45 dias após a semeadura.

A altura das plantas não apresentou diferenças acentuadas entre os diferentes tratamentos (Tabela 1).

Apenas aos 45 dias após a semeadura (DAS), as plantas cujo substrato foi tratado com Raios Gama (Ni - Raios Gama) apresentaram maior crescimento que as plantas inoculadas com Glomus clarum. Os dados da massa da parte aérea seca também indicam pouca diferença entre os tratamentos (Tabela 1). Aos 45 dias após a semeadura, o tratamento com Raios Gama (Ni - Raios gama) apresentava maior massa que o tratamento inoculado com Glomus etunicatum. Aos 79 dias após a semeadura não havia diferenças entre os tratamentos e aos 132 dias o tratamento $\mathrm{Ni}$ - Raios Gama apresentou maior massa que o tratamento inoculado com Glomus clarum. 
Tabela 1. Altura e massa da parte aérea seca de mudas de Mimosa artemisiana com ou sem (Ni) tratamentos de inoculação com fungos micorrízicos arbusculares em diferentes períodos após a semeadura em substrato rico em fósforo.

\begin{tabular}{|c|c|c|c|c|c|c|}
\hline \multirow{3}{*}{ Tratamentos } & \multicolumn{3}{|c|}{ Altura das mudas } & \multicolumn{3}{|c|}{ Massa da parte aérea seca } \\
\hline & 45 dias & 79 dias & 132 dias & 45 dias & 79 dias & 132 dias \\
\hline & \multicolumn{3}{|c|}{---------------------'cm------------------ } & \multicolumn{3}{|c|}{------------------------g g------------------------ } \\
\hline $\mathrm{Ni}$ - Não tratado & $5,26 \mathrm{ab}$ & $17,37 \mathrm{a}$ & $48,54 \mathrm{a}$ & $0,15 \mathrm{ab}$ & $0,46 \mathrm{a}$ & $2,09 \mathrm{ab}$ \\
\hline $\mathrm{Ni}$ - Raios gama & $6,56 \mathrm{a}$ & $19,39 \mathrm{a}$ & $48,74 \mathrm{a}$ & $0,21 \mathrm{a}$ & $0,48 \mathrm{a}$ & $2,33 \mathrm{a}$ \\
\hline $\mathrm{Ni}$ - Benomyl & $5,30 \mathrm{ab}$ & $17,06 \mathrm{a}$ & $46,22 \mathrm{a}$ & $0,16 \mathrm{ab}$ & $0,57 \mathrm{a}$ & $1,74 \mathrm{ab}$ \\
\hline Glomus clarum & $4,76 \mathrm{~b}$ & $16,93 \mathrm{a}$ & $45,34 \mathrm{a}$ & $0,16 \mathrm{ab}$ & $0,55 \mathrm{a}$ & $1,71 \mathrm{~b}$ \\
\hline Glomus etunicatum & $4,80 \mathrm{ab}$ & $19,92 \mathrm{a}$ & 50,66 a & $0,12 \mathrm{~b}$ & $0,58 \mathrm{a}$ & $2,19 \mathrm{ab}$ \\
\hline $\mathrm{CV}(\%)$ & 15,07 & 13,84 & 8,99 & 24,62 & 23,56 & 13,80 \\
\hline
\end{tabular}

Letras iguais nas colunas indicam ausência de diferença entre as médias por Tukey $5 \%$.

Os tratamentos também exerceram pouco efeito sobre a nodulação das raízes (Tabela 2). Aos 45 dias após a semeadura não havia diferenças no número de nódulos. Aos 79 dias após a semeadura, o tratamento Ni - Raios Gama apresentou maior número de nódulos que o tratamento de inoculação com Glomus clarum, porém a massa seca dos nódulos não sustentou esta diferença, não mostrando efeito dos tratamentos (Tabela 2).

Da mesma forma ocorreu aos 132 dias após a semeadura, onde se verificou maior número de nódulos no tratamento $\mathrm{Ni}-$ Raios Gama em relação ao tratamento $\mathrm{Ni}-$ Benomyl, mas a massa dos nódulos não confirmou a diferença.

Tabela 2. Número de nódulos e massa de nódulos secos em Mimosa artemisiana com ou sem (Ni) tratamentos de inoculação com fungos micorrízicos arbusculares em diferentes períodos após a semeadura em substrato rico em fósforo.

\begin{tabular}{|c|c|c|c|c|c|}
\hline \multirow{3}{*}{ Tratamentos } & \multicolumn{3}{|c|}{ Número de nódulos } & \multicolumn{2}{|c|}{ Massa de nódulos secos } \\
\hline & 45 dias & 79 dias & 132 dias & 79 dias & 132 dias \\
\hline & \multicolumn{3}{|c|}{ - } & 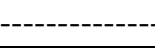 & 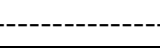 \\
\hline $\mathrm{Ni}$ - Não tratado & $5,00 \mathrm{a}$ & $7,67 \mathrm{ab}$ & $18,80 \mathrm{ab}$ & $0,240 \mathrm{a}$ & $0,333 \mathrm{a}$ \\
\hline $\mathrm{Ni}$ - Raios Gama & $7,46 \mathrm{a}$ & $14,33 \mathrm{a}$ & 23,06 a & $0,260 \mathrm{a}$ & $0,507 \mathrm{a}$ \\
\hline $\mathrm{Ni}-$ Benomyl & $4,46 \mathrm{a}$ & $4,80 \mathrm{ab}$ & $10,20 \mathrm{~b}$ & $0,140 \mathrm{a}$ & $0,262 \mathrm{a}$ \\
\hline Glomus clarum & $4,73 \mathrm{a}$ & $2,60 \mathrm{~b}$ & $15,80 \mathrm{ab}$ & $0,140 \mathrm{a}$ & $0,252 \mathrm{a}$ \\
\hline Glomus etunicatum & $4,93 \mathrm{a}$ & $11,40 \mathrm{ab}$ & $18,50 \mathrm{ab}$ & $0,380 \mathrm{a}$ & $0,357 \mathrm{a}$ \\
\hline $\mathrm{CV}(\%)$ & 63,03 & 60,72 & 33,71 & 66,59 & 50,19 \\
\hline
\end{tabular}

Letras iguais nas colunas indicam ausência de diferença entre as médias por Tukey 5\% 
A altura, massa seca, número de nódulos e massa de nódulos não foram beneficiados com os tratamentos de inoculação de FMAs no solo rico em P. A própria fertilidade do solo, foi suficiente para promover o desenvolvimento das plantas e sua nodulação.

Abbott e Robson (1981) observaram que plantas de trevo apresentaram estímulo ao crescimento quando inoculadas com FMAs, em solo com pequenas doses de superfosfato $(0,5$ a 2,5 g/kg) não ocorrendo o mesmo com as plantas sem P. Pequenas adições de $\mathrm{P}$ aumentaram a porcentagem de raízes colonizadas, porém, maiores acréscimos de $\mathrm{P}$ diminuíram a porcentagem de colonização, sugerindo assim, que o status de P na planta estivesse atuando como um mecanismo de autoregulação da simbiose.

Amijee et al, (1990) também observaram a redução significativa dos benefícios da inoculação com FMAs em alho-porró quando fizeram aplicações de doses mais elevadas de $\mathrm{P}$.

A colonização micorrízica aumentou com o tempo de formação das mudas da Mimosa artemisiana (Tabela 3). Em relação ao tratamento $\mathrm{Ni}$ - Não tratado, os demais tratamentos apresentaram colonização micorrízica superior aos 45 e 79 dias após a semeadura, não diferindo entre si. Aos 132 dias após a semeadura a superioridade da colonização micorrízica em relação ao $\mathrm{Ni}$ - Não tratado foi observada apenas nas mudas inoculadas com Glomus clarum.

$\mathrm{O}$ tratamento $\mathrm{Ni}$ - Não tratado não apresentou-se colonizado nas duas primeiras épocas de avaliação e apresentou baixa colonização aos 132 dias após a semeadura. Não houve diferença entre as duas espécies de FMAs inoculadas quanto à promoção da colonização das raízes.

Tabela 3. Colonização micorrízica e número de esporos de Mimosa artemisiana em $50 \mathrm{ml}$ de substrato em diferentes períodos após a semeadura em substrato rico em fósforo.

\begin{tabular}{|c|c|c|c|c|c|c|}
\hline \multirow[b]{2}{*}{ Tratamentos } & \multicolumn{3}{|c|}{ Colonização micorrízica } & \multicolumn{3}{|c|}{ Número de esporos } \\
\hline & 45 dias & 79 dias & 132 dias & 45 dias & 79 dias & 132 dias \\
\hline$\overline{\mathrm{Ni} \text { - Não tratado }}$ & $0 \mathrm{~b}$ & $0 \mathrm{~b}$ & $17,34 \mathrm{~b}$ & $179 \mathrm{a}$ & $436 \mathrm{ab}$ & $985 \mathrm{a}$ \\
\hline $\mathrm{Ni}$ - Raios gama & $15,41 \mathrm{a}$ & $22,79 \mathrm{a}$ & $31,93 \mathrm{ab}$ & $222 \mathrm{a}$ & $434 \mathrm{ab}$ & $933 \mathrm{a}$ \\
\hline $\mathrm{Ni}-$ Benomyl & $23,96 \mathrm{a}$ & $25,67 \mathrm{a}$ & $25,61 \mathrm{ab}$ & $143 \mathrm{a}$ & $327 \mathrm{~b}$ & $682 \mathrm{a}$ \\
\hline Glomus clarum & $24,68 \mathrm{a}$ & $24,98 \mathrm{a}$ & $40,73 \mathrm{a}$ & $168 \mathrm{a}$ & $545 \mathrm{ab}$ & $1089 \mathrm{a}$ \\
\hline Glomus etunicatum & $18,74 \mathrm{a}$ & $25,20 \mathrm{a}$ & $33,11 \mathrm{ab}$ & $184 \mathrm{a}$ & $552 \mathrm{a}$ & $1232 \mathrm{a}$ \\
\hline $\mathrm{CV}(\%)$ & 47,56 & 38,19 & 30,92 & 39,36 & 23,39 & 32,15 \\
\hline
\end{tabular}

Letras iguais indicam ausência de diferença entre as médias por Tukey $5 \%$. 
A avaliação dos tratamentos não inoculados (Ni) nos indicou que suas colonizações se deviam apenas ao fungo Glomus etunicatum, indicando contaminação por este fungo durante a condução do ensaio. Isto confirma ser este fungo agressivo e capaz de contaminar outros vasos em casa de vegetação como sugerido por Saggin Júnior e Silva, 2002.

Como a contaminação foi rápida nos tratamentos não inoculados tratados com Benomyl e Raios Gama, sugere-se que a eliminação de fungos e outros microrganismos indígenas presentes no substrato tenha favorecido $\mathrm{o}$ estabelecimento do Glomus etunicatum contaminante, enquanto que no tratamento Ni - Não Tratado, houve maior demora no seu estabelecimento.

A contaminação pode ter ocorrido por formigas que estavam grandemente presentes nas bandejas e nas mudas devido ao aparecimento esporádico de cochonilhas Ortesia prellonga durante a condução do experimento, ou por ventos vindos do sistema de refrigeração da casa de vegetação. A contaminação de FMAs pode ocorrer através do transporte dos propágulos dos FMAs pela entomofauna do solo. É muito comum, durante o estágio inicial de recuperação de áreas degradadas que Collembolas, migrem para estas áreas podendo arrastar junto propágulos de
FMAs (DUGER, 1991; SAUTER; SANTOS, 1994).

Quanto à esporulação dos fungos, aos 79 dias após a semeadura, as mudas inoculadas com Glomus etunicatum apresentaram maior número de esporos em relação às mudas tratadas com NiBenomyl, enquanto que aos 45 dias e 132 dias após a semeadura, não houve diferença entre os tratamentos.

Os efeitos dos tratamentos nos teores de nutrientes nas mudas da Mimosa artemisiana encontram-se na Tabela 4.

Os teores de $\mathrm{N}, \mathrm{P}, \mathrm{Ca}$ e $\mathrm{Mg}$ foram pouco influenciados pelos tratamentos. Apenas verificou-se diferenças nos teores de $\mathrm{P}$ aos 79 dias após a semeadura e de $\mathrm{Mg}$ aos 132 dias após a semeadura. $\mathrm{O}$ teor de $\mathrm{P}$ aos 79 dias após a semeadura foi maior no $\mathrm{Ni}$ - Não tratado que no tratamento com Glomus clarum, fato raro quando se compara tratamento micorrizado com não micorrizado, podendo ser justificado devido a um pequeno efeito de diluição em uma condição de consumo de luxo.

Observou-se, que os teores de P estão acima do nível crítico $\left(0,01\right.$ a $\left.0,08 \mathrm{~g} \mathrm{~kg}^{-1}\right)$ de exigência das espécies de leguminosas (MALAVOLTA, 1976). Mas este excesso, não causou problemas para as mudas da Mimosa artemisiana, já que quando este fato ocorre, o "consumo de luxo" é transferido para polifosfatos e outros 
fosfatos, sem afetar o crescimento da planta. O teor de $\mathrm{Mg}$ aos 132 dias após a semeadura foi maior no tratamento $\mathrm{Ni}-$ Benomyl em relação ao tratamento $\mathrm{Ni}-$ Não tratado, estando como o $\mathrm{P}$ acima do nível crítico $\left(0,04 \mathrm{~g} \mathrm{~kg}^{-1}\right)$ de exigência das espécies leguminosas (MALAVOLTA, 1989).

Quanto aos teores de $\mathrm{Ca}$ e $\mathrm{N}$, não houve diferenças significativas entre os tratamentos. A absorção de $\mathrm{Ca}$ pelos fungos micorrízicos arbusculares é pouco importante em condições de boa disponibilidade no solo quando o $\mathrm{Ca}$ é facilmente transportado até a superfície das raízes pelo fluxo de água, (RHODES; GERDEMAN, 1978). Os teores de Ca na parte aérea das mudas da Mimosa artemisiana segundo Malavolta (1989) encontram-se acima das concentrações normais para leguminosas $\left(0,22 \mathrm{~g} \mathrm{~kg}^{-1}\right)$, bem como o $\mathrm{N}\left(0,26 \mathrm{~g} \mathrm{~kg}^{-1}\right)$.

Tabela 4. Teor de nitrogênio, fósforo, cálcio e magnésio na parte aérea de Mimosa artemisiana com ou sem tratamentos de inoculação com fungos micorrízicos arbusculares em diferentes períodos após a semeadura em substrato rico em fósforo.

\begin{tabular}{|c|c|c|c|c|c|c|c|c|}
\hline \multirow{2}{*}{ Tratamentos } & \multicolumn{2}{|c|}{ Nitrogênio } & \multicolumn{2}{|c|}{ Fósforo } & \multicolumn{2}{|c|}{ Cálcio } & \multicolumn{2}{|c|}{ Magnésio } \\
\hline & $79 \mathrm{~d}$ & $132 \mathrm{~d}$ & $79 \mathrm{~d}$ & $132 \mathrm{~d}$ & $79 \mathrm{~d}$ & $132 \mathrm{~d}$ & $79 \mathrm{~d}$ & $132 \mathrm{~d}$ \\
\hline & $302 \mathrm{a}$ & $258 \mathrm{a}$ & 30 & & a & 16 & & 326 \\
\hline $\mathrm{Ni}-$ Raios & $2,97 \mathrm{a}$ & $2,51 \mathrm{a}$ & $2,95 \mathrm{ab}$ & $2,11 \mathrm{a}$ & $18,36 \mathrm{a}$ & $16,82 \mathrm{a}$ & $3,40 \mathrm{a}$ & $3,56 a b$ \\
\hline $\mathrm{Ni}$ - Benomyl & $3,08 \mathrm{a}$ & $2,75 \mathrm{a}$ & $2,78 \mathrm{ab}$ & $2,20 \mathrm{a}$ & $17,60 \mathrm{a}$ & $17,12 \mathrm{a}$ & $3,34 \mathrm{a}$ & $3,78 \quad \mathrm{a}$ \\
\hline Glomus clarum & $3,17 \mathrm{a}$ & $2,77 \mathrm{a}$ & $2,04 \quad b$ & $2,13 \mathrm{a}$ & $17,24 \mathrm{a}$ & $16,12 \mathrm{a}$ & $3,16 \mathrm{a}$ & $3,64 a b$ \\
\hline Glomus etunicatum & $3,13 \mathrm{a}$ & $2,82 \mathrm{a}$ & $2,39 \mathrm{ab}$ & $2,08 \mathrm{a}$ & 15,98 a & $15,64 \mathrm{a}$ & $3,06 \mathrm{a}$ & $3,34 \mathrm{ab}$ \\
\hline $\mathrm{CV}(\%)$ & 8,07 & 7,16 & 15,55 & 8,07 & 13,15 & 11.58 & 10,93 & 6,31 \\
\hline
\end{tabular}

Letras iguais nas colunas indicam ausência de diferença entre as médias por Tukey 5\%. 
Devido à fertilidade elevada do substrato, não houve resposta em crescimento e nutrição à inoculação dos FMAs. Isto é esperado em plantas de média a baixa dependência micorrízica crescendo em substrato rico em fósforo (SIQUEIRA; SAGGIN JÚNIOR, 2001). A disponibilidade de $\mathrm{P}$ não foi suficiente para promover efeitos negativos no crescimento das plantas micorrizadas (SAGGIN JÚNIOR, 1999), permitindo boa colonização das mudas tanto por Glomus clarum quanto por Glomus etunicatum. Ambos os fungos mostraram-se eficientes em colonizar as mudas da Mimosa artemisiana. A boa colonização das mudas é de extrema importância para garantir sua sobrevivência e estabelecimento após o transplante para uma área degradada de baixa fertilidade e com poucos propágulos de FMAs.

As plantas cujo substrato foi tratado com Raios Gama (Ni - Raios Gama) tenderam a apresentar maior crescimento e nodulação sugerindo uma melhor eliminação inicial de microrganismos, o que pode favorecer o crescimento e nodulação pela eliminação de antagonistas, competidores e patógenos. Porém, de maneira geral, houve pouco efeito dos tratamentos. A fertilidade foi suficiente para promover a nodulação mesmo no tratamento menos colonizado por FMAs (Ni - Não tratado) e para não promover efeitos benéficos da inoculação sobre os teores de nutrientes na parte aérea.

Este trabalho evidência a possibilidade de micorrização de mudas de Mimosa artemisiana crescendo em substrato rico em fósforo. Este procedimento mesmo que não reflita em benefícios imediatos no crescimento, nodulação e nutrição das mudas, esperase que favoreça a planta quando transplantada para áreas degradadas.

\section{CONCLUSÃO}

Alto nível de $\mathrm{P}$ no substrato não impede a colonização micorrízica das raízes o que pode garantir boa adaptação das mudas em uma área degradada.

A fertilidade do substrato foi suficiente para garantir o crescimento, nutrição e nodulação das plantas não evidenciando efeitos benéficos da inoculação dos FMAs.

As mudas de Mimosa artemisiana apresentam crescimento lento até 45 dias após a semeadura.

\section{REFERÊNCIAS}

ALlen, O. N.; ALlEn, E. K. The leguminosae a sorce book of characteristics, uses and nodulation. 
London, The University Wisconsin Press,. 812 p. 1981.

ABBOTT, L. K.; ROBSON, A. D. The effect of VA mycorrhizae on plant growth. In: POWELL, C. L.; BAGYARAJ, D. J. V. A mycorrhizal S.I: CRC Press, p.113-130, 1981.

AMIJEE, F.; TINKER, P.B.; STRIBLEY, D.P. The development of endomucorrhizal root system. VII. A detailed study of effects of soil phosphorus on colonization. New Phytologist, Cambridge, Grã-Bretanha, v.111, p.435-446, 1989.

AZCÓN-AGUILAR, C.; BAREA, J.M. Applying mycorrhiza biotechnology to horticulture: significance and potentials. Scientia

Horticulturae,

Amsterdam.v.68, p.1-24, 1997.

CARDOSO, E. J. B. N. Interaction of mycorrhiza, phosphate and manganese in soybean. In: AZCON-AGUILAR, C.; BAREA, J. M. (Eds.). Mycorrhizas in integrated systems from genes to plant development. Luxembourg, Office for Official Publications of the European Communities, 1986. p. 304306.

CARNEIRO, M.A.C.; SIQUEIRA, J.O.; VALE, F.R; CURI, N. Limitação nutricional e efeito do pré-cultivo com
Brachiaria decumbens e da inoculação com Glomus etunicatum no crescimento de mudas de espécies arbóreas em solo degradado. Ciência e Prática, Lavras, v.19, n.3, p.281-288, jul./set, 1995.

COLLOZZI-FILHO, E.; SIQUEIRA, J.O. Micorrizas vesiculo-arbuscular em mudas de cafeeiro: 1 - Efeitos da Gigaspora margarita e adubação fosfatada no crescimento e nutrição. Revista Brasileira de Ciência do Solo, v.10, p.119-205, 1986.

CHU,E.Y.; MOLLER, M.R.F.; CARVALHO, J.G. Efeito da inoculação micorrízica em mudas de gravioleira em solo fumigado e não fumigado. Pesquisa Agropecuária Brasileira, Brasília, v.36, n.4, p.671-680, 2001.

DIAS, L. E.; CAMPELLO, E. F. C.; MELLO, J. W. V. Uso de Leguminosas Associadas a Microrganismos na Revegetação de Áreas de Mineração em Paracatu, MG. Convênio Rio Paracatu Mineração S.A./FUNARBE. Relatório de atividades desenvolvidas no período de dezembro de 1994 a dezembro de 1997. Viçosa, 71 p, 1998.

DUNGER, $\mathrm{M}$ W. Arthropods in primary succession. In: Proc. $4^{\text {th }}$ ECE/XIII. Godollo. SIEEC, 1991. p.696-702. 
FERNANDES, A. B.; SIQUEIRA, J. O.; MENEZES, M. A. L.; GUEDES, G. A. A. Efeito diferenciado do P sobre o estabelecimento e efetividade da simbiose endomicorrízica em milho e soja. Revista Brasileira Ciência do Solo, Campinas, v.11, n.2, p.101-108, maio/ago.1987.

FERREIRA, D. F. Sistema de análise estatística para dados balanceados. Lavras: $\quad$ UFLA/DEX/SISVAR, 1998. $145 \mathrm{p}$.

FRANCO, A.A.; BALIEIRO, F. de C. The role of biological nitrogen fixation in land reclamation, agroecology and sustainable of tropical agriculture. In: ROCHA-MIRANDA, C.E. Transition to global sustainability: the contribution of Brazilian Science. Rio de Janeiro: Academia Brasileira de Ciências, 2000, p. 210-233.

FRANCO, A. A.; DIAS, L. E.; FARIA, S. M. de; CAMPELlO, E. F. C.; SILVA E.M.R. Uso de leguminosas florestais noduladas e micorrizadas como agentes de recuperação e manutenção da vida do solo: um modelo tecnológico. In: ESTEVES, F.A. de. Estrutura, funcionamento e manejo de ecossistemas brasileiros, S.I.p., 1996. p.459-467.
FRANCO, A.A.; CAMPELLO, E.F.C.; DIAS, L.E. \& FARIA, S.M. Revegetation of acidic residues from bauxite mining using nodulated and mycorrhizal legume trees. Nitrogen Fixing Trees Research Reports (special issue). p. 313-320. 1995.

FRANCO, A. A.; CAMPELLO, E. F. C.; SILVA, E. M. R.; FARIA, S. M. Revegetação de solos degradados., Seropédica, R.J., EMBRAPA/CNPBS, 1992. 11p. (Comunicado Técnico 9).

GERDEMANN, J. W.; NICOLSON, T. H. Spores of mycorrhizal endogone species extracted from Transaction of the Bristish Nycological Society, soil by wit sieving and decanting. Trans. Br. Mycol. Soc., London, v. 46, p. 235-244, 1963.

GIOVANNETTI, M.; MOSSE, B. An evaluation of techniques to measure vesicular-arbuscular mycorrhizal infection in roots. New Phytologist., Oxford, v. 84, n.3, p. 484-500, 1980.

GRACE, C; STRIBLEY, D. P. A safer procedure for roution staining of vesicular - arbuscular mucorrhizal fungi. Mycological Research, Cambridge, v.95, n.10 p.1160-1162, 1991. 
HERINGER, E.P; PAULA, J.E. Um novo par vicariante: Mimosa artemisiana Heringer \& Paula (floresta atlântica) e Mimosa schomburgkii Benth (floresta amazônica). Anais da Sociedade Botânica do Brasil, Rio de Janeiro. v.30, p.75-82, 1979.

IBAMA. Manual de recuperação de áreas degradadas pela mineração. Brasília, IBAMA, 96 P.1990.

JANOS, D.P. Mycorrhizas, succession and the rehabilitation of deforested lands in the humid tropics. In: FRANKLAND， J.C.;MAGAN， N.; GADD,G.M. (Eds.). Fungi and environmental change: British Mycological Society Symposium. Cambridge, UK: Cambridge University Press, 1996.v.20, p.129-162.

JASPER， D. A; ABBOTT, L.K.; ROBSON, A.D. The effect of soil disturbance on vesicular-arbuscular mucorrhizal fungi in soils from different vegetation types. New Phytologist, Oxford, v. 118, p. 471-476, 1991.

JENKINS, W. R. A rapid centrifugalfloration technique for separatin nematodes from soil. Plant Dis. Rep. 48: 692, 1964.

JESUS, R.M. Revegetação: da teoria a prática. Técnicas de implantação. In:
SIMPÓSIO SUL-AMERICANO, 1.; e SIMPÓSIO NACIONAL DE RECUPERAÇÃO DE ÁREAS DEGRADADAS 2., Foz do Iguaçú, 1994. Anais, Curitiba, FUFEF, 679 p, 1994.

KAMINSKI, J.; RHEINHEIMER, D. dos S. Micorrização da Pensacola afetada por culturas precedentes. II. Taxa de crescimento e absorção de fósforo. In: REUNIÃO BRASILEIRA SOBRE MICORRÍZAS, II, 1994. Florianópolis, $\mathrm{SC}$. Resumos...Florianópolis, 1994, p.38.

KOSKE, R.E.; GEMMA, J.N. Amodified procedure for stining roots to detect VA mycorrhizas. Mycological Research, Cambridge, v.92, n.4, p.486488, June 1989.

MAJER, J.D. Fauna studies and land reclamation technology: a review of the history and need for such studies. In: Animals in primary succession: the role of fauna in reclamed lands, J.D. Majer, coordinator, Londres: Cambridge University Press, 1989. p. 3-33.

MALAVOLTA, E. Manual de química agrícola; nutrição de plantas e fertilidade do solo. São Paulo: Agronômica Ceres, 1976. 528 p. 
MALAVOLTA, E. Avaliação do estado nutricional das plantas: princípios e aplicações. Piracicaba: Associação Brasileira para Pesquisa da Potassa e do Fosfato, 1989. 201 p.

MIRANDA, J. C. C.; SOUZA, D. M. G.; MIRANDA, L. N. Influência de fungos endomicorrízicos vesículoarbusculares na absorção de fósforo e no rendimento de matéria seca de plantas de sorgo. Revista Brasileira de Ciência do Solo, Campinas, v.8, n.1, p.31-36, jan/abr.1984.

MOREIRA, F. M. S.; SIQUEIRA, J. O. Microbiologia e bioquímica do solo. Lavras: Editora UFLA, 2002. 626p.

NEWNAN, E.J. A method of stimating the total lenght of root sample. Journal of Applied Ecology, Oxford, 3: 13945, 1966.

NEWSLETTER WWI-UUA. Revista árvore, 2002.

OLDEMAN, L.R. The global extent of soil degradation, In: Soil Resilience and Sustainable Land Use. GREENLAND, D. J.; SZABOCLS, I (Eds). Cab International, Wallingford, UK. 1994. p. 99-118. ODUM, E.P. Ecologia . Rio de janeiro, ed. Guanabara, 434 p. 1988.
PARROTA, J.A. The role of plantation forest in rehabilitating degraded tropical exosystems. Agric. Ecosyst Environ.; Amsterdam, v. 41, p. 115-133, 1992.

PERRY, D. A.; MOLINA, R.; AMARANTHUS, M. P. Mycorrhizae, mycorrhizospheres and reforestation: current knowledge and research needs. Can. J.of Forest Res., v.8, n.17, p.929940, 1987.

RHEINHEIMER, D.S.; ERNANI, P.R.; SANTOS, J.C.P. Influência da micorriza no crescimento do Trifolium riograndense e na predição de absorção de fósforo por um modelo mecanístico. Revista Brasileira de Ciência do Solo. Campinas, v.21, p.191-197, 1997.

RHODES, L. H.; GERDEMAN, J. W. Translocation of calcium and phosphate by external hyphae of vesicular arbuscular mycorrhizae. Soil Science, Baltimore, v.126, n.2, p.125-126, 1978.

SAUTTER, K. D.; SANTOS, H. R. dos. Avaliação da estrutura da população da mesofauna edáfica, em diferentes regimes de reabilitação de um solo degradado pela mineração do xisto. Revista Set. Ciência.Agrária, v. 13, n. 1-2, p. 31-34, 1994.

SILVA, F.C.; Manual de análises químicas de solos, plantas e 
fertilizantes. Embrapa Solos, Embrapa Informática Agropecuária - Brasília; 1999.

SILVA, E. M. R da; BOVI, M. L. A. Estabelecimento de mudas de palmiteiro (Euterpe edulis) inoculados com fungos micorrízicos vesículo-arbusculares. In: REUNIÃO BRASILEIRA SOBRE MICORRIZAS, Florianópolis, 1994. Resumos. Florianópolis, Universidade Federal de Santa Catariana, p.35, 1985.

SIQUEIRA, J. O.; FRANCO, A. A. Biotecnologia do solo: Fundamentos e Pespectivas. Lavras: MEC/ABEAS, 236 p, 1988.

SIQUEIRA, J. O.; MOREIRA, F. M. S.; GRISI, B. M.; HUNGRIA, M.; ARAUJO, R. S. Microorganismos e processos biológicos do solo: perspectiva ambiental. EMBRAPA, Brasília: EMBRAPA, 1994. 142 p.

SIQUEIRA, J. O.; SAGGIN-JUNIOR, O. J. The importance of mycorrhizae association in natura in low fertility. In: Machado, A. T. Poc. Int. Symposium on Environmental Stress: maize in perspective. Anais... Sete Lagoas: EMBRAPA, p. 240-280, 1995.

SIQUEIRA, J. O.; SAGGIN JÚNIOR, J. O. Dependency on arbuscular mycorrhizal fungi and responsiveness of some Brazilian native woody species. Mycorrhiza, v. 11, p. 245-255, 2001.

VICENT, J. M. A manual for the practical study of root-nodule bactéria. Oxford Blackwell scientific publications, Oxford, 164p, 1970. 